\title{
Neurocysticercosis, immune status and immune response
}

Neurocisticercose, estado imunológico e resposta imune

Beuy Joob', Viroj Wiwanitkit²

'Sanitation 1 Medical Academic Center, Bangkok, Thailand;

${ }^{2}$ Wiwanitkit House, Bangkhae, Bangkok, Thailand.

Correspondence: Beuy Joob; Sanitation 1 Medical Academic Center; Bangkok - Thailand; E-mail: beuyjoob@hotmail.com

Conflict of interest: There is no conflict of interest to declare.

Received 20 April 2012; Received in final form 01 May 2012; Accepted 08 May 2012

Dear Editors,

A recent paper on neurocysticercosis and immune suppression is of interest ${ }^{1}$. Indeed, several observations on the co-occurrence of neurocysticercosis and immunosuppression can be seen. However, further studies are still required to conclude for any relationship. To develop any infection, the poor immune status of the affected patient must be accompanied. The host and parasite immune interaction seems to be a complex phenomenon. Focusing in neurocysticercosis, this is a chronic infection and the short-term evaluation of the immune status might not give the correct explanation on the findings. The detected immunosuppression might or might not be directly relating to the infection. Of interest, in tropical countries such as Thailand, there is still no evidence that neurocysticercosis increases its incidence among the immunodeficient subjects, such as HIV seropositive, and so on.

\section{References}

1. Bueno EC. Cysticercosis and the immunossupression: what are the mechanisms involved? Arq Neuropsiquiatr 2012;70:243-244. 